\title{
Lapurdum
}

Euskal ikerketen aldizkaria | Revue d'études basques |

Revista de estudios vascos | Basque studies review

Numéro spécial 2 | 2015

Othoi çato etchera

\section{Edizioaren aurkezpena}

Manuel Padilla-Moyano et Charles Videgain

\section{OpenEdition \\ Journals}

Édition électronique

URL : https://journals.openedition.org/lapurdum/2559

DOI : 10.4000/lapurdum.2559

ISSN : 1965-0655

Éditeur

IKER

Édition imprimée

Date de publication : 1 octobre 2015

Pagination : 87-92

ISBN : 978-2-9553413-1-5

ISSN : $1273-3830$

\section{Référence électronique}

Manuel Padilla-Moyano eta Charles Videgain, «Edizioaren aurkezpena», Lapurdum [Linean], Numéro spécial 2 | 2015, Sarean emana----an 25 juillet 2016, kontsultatu 02 avril 2023. URL: http:// journals.openedition.org/lapurdum/2559; DOI: https://doi.org/10.4000/lapurdum.2559

\section{@) $(\Theta \Theta \Theta$}

Creative Commons - Attribution-NonCommercial-NoDerivatives 4.0 International - CC BY-NC-ND 4.0 https://creativecommons.org/licenses/by-nc-nd/4.0/ 


\title{
Edizioaren aurkezpena
}

\author{
Manuel PADILLA MOYANO ${ }^{1} \&$ Xarles VIDEGAIN²
}

\section{Iturria}

Lan honetan lapurterazko berrogeita hamar gutunen multzoa argitaratzen dugu. Dokumentazioa Londreseko the National Archives agiritegian gordetzen dute, hain zuzen High Court of Admiralty sekzioan, HCA 30/264 kutxan.

\section{Gutunen hurrenkera}

Gutunek badute High Court of Admiralty delakoan ezarri zenbakuntza bat; zenbaki horiek letra etzanaz transkribatu ditugu. Baina gutunak ez ditugu hurrenkera horretan ematen: irizpide kronologikoa hobetsirik, dataren arabera antolatu ditugu, zenbakuntza berria ezarriz. Ondorioz, $1757 \mathrm{ko}$ otsailaren 2 an datatua den gutunak 1. zenbakia du, eta apirilaren leko data duenak 48. zenbakia. Badira bi eskutitz ber gutun-azalean; hauei 36a eta 36b zenbakiak esleitu zaizkie. Azkenik, 49. zenbakia duenak ez du datarik.

\section{Orrialdeztapena}

Orrialdeztapena ezarri dugu, gutun-azala ere kontuan hartuz, $<>$ karakteren artean, eta orrialdeen adierazteko ohikoa den recto / verso sistemari jarraikiz. Beraz, $<20.3 \mathrm{v}>$ honela ulertu behar da: 20. gutunaren hirugarren orriaren gibelaldea edo verso.

\section{Testuaren bertsioak}

Testu baten eskaintzean zein irakurle motari zuzentzen zaion gogoetatzea komeni da. 
Hortaz, Le Dauphin gutuneriaren kasuan bi profil idurikatu dugu: bata interes filologikoa duen irakurlearena, grafia zaharretan laketua; bestea gutunen mamian sartu nahi duen irakurlearena da, behialako konbentzio grafikoen axolik gabea. Bi irakurle mota horiek gogoan, bi bertsio adelatu ditugu, ezaugarri aski markatuak dituztenak: 1) bertsio paleografikoa, jatorrizko dokumentuen ñabardura grafikoak jasotzen dituena; eta 2) bertsio eguneratua, egungo ohiko irakurleak espero duen itxurarekin, irakurtzeko ekintza oztopa lezakeen ahalbait elementu gutien ageriz.

\subsection{Bertsio paleografikoa}

a. Grafiak guztiz errespetatzen dira, salbu s luzeak.

b. Hitz zatiketa mantentzen da.

c. Puntuazioa, letra larri eta xehea iturrian diren bezala jasotzen dira.

d. Paragrafoen antolaketa mantentzen da. Lerrokatzea / karakteraren bidez adierazia da. Lerroen zenbakuntza paperaren goihenean agertzen diren hitzetarik abiatzen da, normalki datatik. Zenbaki hauek bost lerro oro adierazten dira.

e. Iturriaren jatorrizko eransketak, gain edo azpi idatziak, superindize edo subindize deitu letra motaren bidez markatuak dira.

f. Hitz barratuak barraturik transkribatuak dira.

g. Laburdurak ez dira garatzen.

h. Ediziogileek erantsia, izan dadin papera higatua delako, izan dadin beste zein-nahi arrazoinengatik, taketen artean emana da, adibidez Martin [de] arrunde.

i. Ezin irakurriak eten puntuekin markatzen dira, taketen artean: [...]. Hizkiak bereizi arren interpretaziorik egin ahal izan ez delarik, crux desesperationis delakoa erabili da $(\dagger)$.

j. Edizio kritiko bat izan gabe, hutsen berri ematen da oharretan. Orobat gertatzen da interpretazio arazoekin, eta aieruen bidezko zuzenketak edo osaketekin.

\subsection{Bertsio eguneratua}

a. Grafiak egungo usantzaren arabera moldatzen dira (ikus \& 5).

b. Hitz zatiketa egungo ohitzen arabera ezarri da, salbu aldaketa morfonologikoak islatuak direnean, nagusiki adizkietan: escara $\rightarrow$ ezkara 'ez gara'.

c. Puntuazioa moldatu da. Erran behar da gutunen puntuazioa minimoa dela, nekez agertzen baita puntuazio zeinurik. Puntuazioaren emateak interpretazio ariketa dakarrela onarturik, zenbaitetan dudak ageri dira; halakoetan duda hori adierazten dute ediziogileek.

d. Paragrafoen antolaketa bertsio paleografikoarena da, beraz eskuizkribuan dena. Eskuizkribuaren lerrokatzea ez da adierazten, alboan datzan bertsio paleografikoan ageri baita.

e. Eransketak, azpi ala gainidatziak, letra molde arruntaz ematen dira.

f. Elementu barratuak ezabatu dira; halako informazioaren gose denak bertsio paleografikora edo faksimilera jo beza.

g. Laburduak garatu dira $(b \rightarrow$ bai), baina ez egungo frantsesean arras ohikoak direnean: $M^{r}, S^{t}$. 
h. Osatutako irakurketak, halaber, ez dira markatu.

i. Ezin irakurriak eten puntuekin markatzen dira, taketen artean: [...]. Hizkiak bereizi arren interpretaziorik egin ahal izan ez delarik, crux desesperationis delakoa baliatu da $(\dagger)$.

j. Bertsio hau ez da edizio kritiko bat; edizio paleografikoak proposatzen dituen zuzenketak eta interpretazioak barneratzen ditu, erreferentziarik egin gabe.

\section{5. $B$ bertsioaren eguneratze grafikoaz}

\subsection{Irizpide orokorrak}

Egokitze grafiko honek ez dakar aldakuntzarik hizkuntzan. Hots, ez da neholaz ere egungo euskarari begira egina den egokitzapena: soilik kontu grafikoa da, grafia zaharrekin ohitua ez den irakurlearen gutunei buruz hurbiltzen laguntzeko. Beraz, testuaren itxura fonetikoa errespetatua da kasu guztietan. Le Dauphin-eko gutunetan kasik eskutitz bederak sistema grafiko propioa du; honek franko zaildu du lana. Luzegi litzateke obratu diren aldaketa guztien berri zehatza ematea hemen, eta debaldekoa: irakurleak bertsio paleografikoa zein eguneratua ditu parez pare. Hona kasu aipagarrienak baizik ez ditugu ekarriko:

a. Txistukariek zailtasun handienak kausatu dituzte. Haiei atal berezia eskaintzen zaie (ikus § 5.2).

b. Herskari hasperendunak gutun gehienetan ez dira bereizten, eta ezin has bereizkuntza grafikorik berrezartzen. Halakoak dudarik gabe ageri direnean ohiko $p h$, th, $k$ h digrafoekin transkribatu ditugu. Ezpainkaria oso bekanki ageri da: aphur, appheza, apparancias $\rightarrow$ aphur, apheza, apharantziaz. Horzkaria maiztxoago: attora, mothela $\rightarrow$ athorra, mothela. Aldakortasun grafiko nabariagoa agertzen du [kh] hotsak: markhatçen, luqainca, luchainca, oqhasione, occasionias $\rightarrow$ markhatzen, lukhainka, okhasione, okhasioniaz. Nehork oposa lezake occasionias formaren gibelean grafia etimologikoa datzala, baina horrek ez luke gure interpretazioa deusetan galaraziko.

c. Dardarkarien adierazpen grafikoa ere defektiboa da, maiz <r> grafema bakarra delarik: beri, gorija, asare $\rightarrow$ berrija, gorrija, asarre. Dardarkari anizkunen eta ttap direlakoen arteko bereizkuntza ezarri dugu egungo irizpideen arabera.

d. Hots sabaikariei doakienean, eta Lapurdin ezagunak diren despalatalizazio fenomenoez kontzient, testuak hots sabaikariak ematen dituenean egungo grafia ez zaigu beti aski. Hortaz, seinale [ ś e j' $n$ a le ] nahiz señale [ ś e' n a le ] dira posible, edo-tzaile [ e $\gamma$ or 'ts a j le ] nahiz-tzaille/-tzalle [ e $\gamma$ or' ts a $K$ e ]. $<\mathrm{tt}>$ digrafoak inoiz [c] hotsa adierazten ahal du (Cattalin, Marittipo), baina gehienetan grafia etimologiko hutsa da (lettra). Aipamen berezia merezi du [n] hotsak: <ñ $>$ grafema nagusi da (ciñean, çhangriñec), baina à la française ere aise atzematen dugu (gagnian, baignan); gainera, 34. gutunean badira grafia hiperkarakterizatuak, lehengoen sintesi gisara: egiñgña, gaiñgñeraco, qusiñgña, baingno, gaingneraquan. Finean, ez da falta [f] hotsaren agerpen argia $<\mathrm{d}>$ grafiaren gibelean: letra sainderiq, 


\section{Domindinaq $\rightarrow$ letra saindderik, Dominddina.}

e. Grafia etimologikoak kasu gutitan ageri dira. Lettra ohikoaz gain, gratia edo occationnia kausitu dugu —azken hau hiperzuzenketa etimologiko gisa entelega daitekeela—. Halakoetan ere grafia egokitu dugu: letra, grazia, ok(h)asionia.

f. Eguneratze grafiko orokor honetan, salbuespen bakarra jende izenei doakie. Izan ere, egungo euskaldunek izen-deiturak lehenago grafietan idazten jarraitzen duten Iparraldean ez luke zentzu handirik XVIII. mendeko izenen Euskaltzaindiaren arauetara ekartzea. Salbuespen bakanak batez besteko irakurleari konprenitzea zailduko litzaiokeenetan dautza: Dihitx $\rightarrow$ Dihitz, edo zenbait hipokoristiko edota ezizenen kasuan: Curjbel $\rightarrow \rightarrow$ Zuribeltz.

g. Beste hizkuntzen agerpenaren kasua (praktikan frantsesa) soilik hitz katearen zatiketari doazkion aldaketak egin dira, gutunen egileek baliatu zituzten grafiak kanbiatu gabe.

\subsection{Txistukarien adierazpen grafikoaz: arazoak eta irizpideak}

Txistukariek aipamen berezia merezi dute, haien islatze grafikoak arazo franko ematen ohi duelako. Lehena apikarien eta bizkarkarien arteko bereizkuntzari doakio, grafietan ez baita beti argia. Batzuetan pentsatzen ahal da grafien erabilera zalantzazkoa den, edo defektiboa; aldiz, beste zenbaitetan testuak bide emaiten du pentsatzeko txistukarien bi sail horien artean bat etortze edo neutraltzea gauzatua datekeela. Bigarren arazoa afrikazioarena da: idazle gehienek ez dute grafikoki adierazten. Bistan da, kasu guztiak ez dira berdinak: nehoiz egorzeko edo ninzela bezalako ahoskatzeak posible izan badira, nekez imajina ditzakegu Exeberri edo eskribazen tankerakoak. Ekar dezagun zenbait gutunen kasua, Le Dauphin bilduman aurki daitezkeen ereduen etsenplutako:

- Martin de Arrunderen txistukarien sistema grafikoa (1. gutuna) beste hainbat gutunetakoa baino argiagoa da. Igorle honek maiz bereizten ditu bizkarkariak eta apikariak, afrikatuak ez direnean bederen. Bizkarkariak <c> grafemaz irudikatuak dira kokagune guztietan: cerbeit, cato, erecibitu, ec. Apikarietan <s> nahiz <ss> aurkitzen ditugu: ossasuna, jrrisca. Banaketa argia da, salbu herskari aurrean, non beti $<\mathrm{s}>$ markatzen baitu: escribacen, jrrisca baina baita caspi, tuste ere. Bizkarkariak hitz bukaeran <c> batez ematen dituela gogoan izanik, zilegi da pentsatzea herskari aurrean neutraltze edo bat etortzea gertatu dela; hauxe da, hain zuzen, fenomenoaren testuinguru fonologikorik errazena. Afrikatuen adierazpena defektiboa da, hein handi batean. Bizkarkarien sailean <c> agertzen da bokalartean (escribacen, cerbicutic, cerbicarry) eta $<\mathrm{x}>$ hitz bukaeran (balix), baina ozen ondoan ere beti <c> emateak ez du afrikazioa bermatzen: nincen, unci, arcen. Apikari afrikatuen agergune bakarra corsurat izanik, zaila da ondoriorik idokitzea. Sabaikariak, aldiz, <ch> digrafoaz markatzen ditu Arrundek: echerat. Gutun honen sistema grafikoak, beraz, bide ematen digu apikari eta bizkarkarien arteko bereizte grafikoa egungo usantzen arabera adierazteko, bi salbuespenekin: 1) herskari aurrean, daroskitzut edo zaspi emateak logikoa dirudi; 2) ozen ondoan. 
- Gacina de Biscarrondok ( $3 \& 4$ ) banaketa grafiko argiago bat ezartzen du afrikatuen markatzeko. Horren adibideak ditugu hala bizkarkarietan (hainits, gastiatcias, egortcen, baitcaite) nola apikarietan (oxalen, etxituba, esxituba). Afrikatugabeetan, Biscarrondok hitz bukaeran eta herskari aurrean beti $<$ s $>$ baliatzen du: dosquicut, emastea, estucube, otoisten, partes, osabas, nais... Bizkarkari eta apikarien neutraltzearen zantzuak ote? Hala bada, neutraltzea herskari aurrean ez ezik, hitz bukaeran ere gauzatuta zegokeen gutun egile honen hizkeran. Baina ezin dugu beste aukerarik baztertu.

- Mari Darbururen (20. gutuna) sistema grafikoak afrikatu vs. ez afrikatu oposizioa lehenesten du, apikari/bizkarkarien arteko bereiztea baino. Idazle hau, hain zuzen, txistukari afrikatuen adierazpen sistematikoa egiten duten gutiengokoa da. Aldiz, ez du afrikazio puntuaren axolik: bajex, saflenxat, cuxaturic, corxura, perxecutatuba, biscoxac, exetit, hemenxe. Ez-afrikatuetan <s> grafemaz zerbitzatzen da, salbuespen bekanekin: baisic, bulus, estauquinat, deusere, costara, gasoa... baina naisseno, jcaten.

- Marittipo de Subietek (27) txistukarien bereizmen zehatzenetakoa baliatzen du. Apikariak et bizkarkariak beti desberdintzen ditu, eta kokagune guztietan: cenbait, zure, zazpi, denbraz, gaztigatcen, ganaizkquitzuun, baitzaituzte, saratarrec, ossaassun, anglessez... Gehiago dena, afrikatuetara hedatzen du bereizmen hori: aguitz, bertce, egortzen, hotsic, cortsuan baina esparanza, gorainci, dabilza.

Txistukari apikari eta bizkarkarien arteko neutraltzeaz denaz bezainbatean, onartzen da fenomenoa mendebaldetik ekialdera hedatu zela. Azken saioek uste genuena baino zabalduago egon zitekeela proposatu dute, Gipuzkoan ere. Norabide bakarreko hedakuntza baino gehiago hainbat irradiazio gunetarik zabaldutako berrikuntza gisa ikusten dute. ${ }^{3}$ Aldiz, guti erran da fenomeno honek Lapurdin ezagut zezakeen garapenaz. Gure ustez, baliteke neutraltzearen zantzuak kausitzea, kostaldean bederen.

Ezin ahantz, ordea, Le Dauphin gutuneria Hegoaldeko testuen analisitik bereizten duen faktore bat: frantsesaren ortografia. Batetik, frantsesak ahoskabe/ahostun oposizioa du, eta artikulazio guneari doakionean bi serie baizik. Beharbada hainbat gutunetan aurkitzen dugun <sS> digrafoa frantses grafiaren zordun da (txistukari ahoskabeetan du baliatzen): ossassuna, ossaba, asserre bezala dossuna, essaguturic, darocussun tankerakoetan ere. Bestetik, baliteke frantsesaren zenbait sekuentzia grafikok eragina ukan lezan Iparraldeko euskaldunengan. Adibidez, frantsesez st anitzez aiseago agertzen da zt baino, eta horrek dudatan jar dezake emaste, gastiga bezalakoen neutraltze kasuentzat hartzea.

3. Atutxa, Udane \& Zuloaga, Eneko. La neutralización de las sibilantes en vasco: una perspectiva diacrónica. XXVIII Congreso Internacional de la Asociación de Jóvenes Lingüistas, Iruñea, 2013ko urria). 
Erranak erran, txistukarien neutraltzearen aztertzea urrun da lan honen helburuetatik. Gure aldetik, Le Dauphin-en lapurterazko gutuneria jartzen dugu ikertzaileen eskuetan, halako gonbita luzatuz. Hortaz, aitzinetik gaztigatu nahi genuke edizio honetan zailtasun handiak aurkitu ditugula txistukarien agerpen grafiko eguneratu koherente eta sistematiko bateraino heltzeko. Azkenean, edizioaren bertsio modernizatuan honako irizpideen arabera egokitu ditugu txistukarien grafiak:

- Apikari eta bizkarkarien arteko oposizioaren beti islatzea, hainbat gutunetan balizko neutraltze baten zantzuak aurkitu arren. Beraz, aispa, emaste, escara $\rightarrow$ aizpa, emazte, ezkara bezala eman ditugu. Berdin hitz bukaeran: osabas, nais, bihotces $\rightarrow$ osabaz, naiz, bihotzez.

- Txistukari afrikatuak egungo ohituren arabera ematea, nahiz gutunetan agerpen grafikoa askotan defektiboa izan. Horrela, bizkarkarietan darosquitcut, darosquicut, dausquitçut $\rightarrow$ darozkitzut, dauskitzut; desiracen, gibelaxen $\rightarrow$ desiratzen, gibelatzen, edo hainits, haynitx, hanix $\rightarrow$ ha(i)nitz. Berdin apikari afrikatuekin: exitu, esxituba, etxituba $\rightarrow$ etsi; urax $\rightarrow$ urrats. Sabaikarien sailean $<t c h>,<$ ch $>$ eta are $<c>$ egungo $t x$ digrafoan biltzen ditugu.

- Ozen ondoko txistukarien markatzea, nahiz jatorrizko grafian ez izan: goraintzi, egortze. Hau da puntu ilunena eta, menturaz, eztabaidagarriena. Denetarik ikusi dugu: gutun batzuetan ez da sekulan markatzen, beste batzuetan hautazkoa da, eta gutiengo batean aski sistematikoa. Kokagune partikular honetan, gutun egile bakoitzaren balizko mintzoaren errespetatzeko desira muturreraino eraman nahiak, soilik grafian oinarriturik, beharbada zenbait inkongruentzia ekar lezake. Goraintzi hitza da honen erakusgarri: bokalismoa gora behera, gorainci / goraintci grafiak lehiatzen dira. Edo egorce / egortce parea, gutun berean agertzera afrikazioaren aldeko argudio sendoa ematen ligukeena. Bestalde, ezaguna da lapurteraren tradizioak unzi, galza bezalako formak lekukotzen dituela. Gutun baten grafia sistema koherente batek hala sujeritzen duenean, halako salbuespenik egin dugu. Adigarri batentzat, 49. gutunaren idazleak, Francha Barrere andereak, ongi markatzen ditu ozen ondoko afrikatuak, baina marçhandiçac idazten du. Kasu honetan marxandizak egokitu dugu, anitz euskaldunek hala ahoskatu dutelako seinale, eta ahoskatzen.

Azken finean, kontzient gara adierazitako irizpideek txistukarien egokitzapen grafiko modernoa dakartela, menturaz modernoegia, eta hartu erabakiak beharbada ez zaizkiela deneri gustatuko. Bainan ezinbestekoa iruditu zaigu gutxieneko irizpide batzuen finkatzea gutun guztiendako. Gai honen inguruko interesa duenak, beraz, jo beza testuaren bertsio paleografikora, edo nahiago badu argazkietara. 